Molecules 2002, 7, 854

molecules

ISSN 1420-3049

http://www.mdpi.org

Commentary

\title{
The International Symposium on Frontiers in Molecular Science 2002 (ISFMS 2002), Qingdao, China, July 15-18, 2002
}

\section{$\underline{\text { Shu-Kun Lin }}^{1,2}$ and Xianguo $\mathrm{Li}^{3}$}

${ }^{1}$ Molecules Editorial Office, Ocean University of Qingdao, Qingdao 266003, Shandong Province, P. R. China. Tel. \& Fax: (+86) 532203 1522; Tel.: (+86) 5322031860 (office direct line); E-mail: linsk@ouqd.edu.cn; Webpages: http://www.mdpi.org/moleculesor http://molecules.ouqd.edu.cn

2 Molecular Diversity Preservation International (MDPI), Matthaeusstrasse 11, CH-4057 Basel, Switzerland. Tel.: (+41) 79322 3379; Fax: (+41) 61302 8918; E-mail: Lin@mdpi.org

${ }^{3}$ College of Chemistry \& Chemical Engineering, Ocean University of Qingdao, Qingdao 266003, P. R. China. Tel.: (+86) 532 2032482, ext. 8318, (+86) 13687678572 (Mobile); Fax: (+86) 5322032483; E-mail: $\underline{\text { lixg@ mail.ouqd.edu.cn }}$

The International Symposium on Frontiers in Molecular Science 2002 (ISFMS 2002) was successfully held in Qingdao, P.R. China, between July 15-18, 2002, with the attendance of 213 participants from 17 different countries. Four Nobel Laureates and 40 other distinguished scientists gave invited lectures at the meeting, while 262 contributed papers and 97 posters were also presented by the conference attendees within the appropriate parallel sessions. Compilation and editing of the conference proceedings is currently underway for publication in a special volume of Molecules.

(C) 2002 by MDPI (http://www.mdpi.org). Reproduction is permitted for noncommercial purposes. 